\title{
Navigation of Several Links Robot Arm based on an Intelligent System
}

\author{
Ivan Isho Gorial \\ Mechatronics Engineering \\ Branch, Control and Systems \\ Engineering Department, \\ University of Technology, \\ Baghdad
}

\begin{abstract}
This paper suggests a navigation structure in three dimensions space based on an intelligent system of a robot several links. The proposed planning system is consisted of several links and separation fuzzy logic stages which control autonomously every manipulator joint. The aim is to move the arm from a required configuration to a desired goal configuration. Two tests are run and modeled in MATLAB. Simulation results show good performance for the proposed scheme that the robot reaches the goal configuration successfully with minimum error and different program iterations in each run in terms of joints angular position respectively for several links in space.
\end{abstract}

\section{General Terms}

Intelligent system, serial robot.

\section{Keywords}

Joint space, path planning, fuzzy logic, planner robot arm, several links.

\section{INTRODUCTION}

A robot manipulator is an electronically controlled mechanism, comprising of various fragments, that performs tasks by cooperating with its surroundings. They are additionally commonly referred to as robotic arms. Robot manipulators are widely utilized in the industrial manufacturing sector and also have numerous other specific applications. Manipulators are composed of an assembly of links and joints. Links are defined as the inflexible sections that make up the mechanism and joints are defined as the connection between two links. The device attached to the manipulator which interacts with its environment to perform tasks is called the end-effector [1]. The accuracy and complexities of positions of robots may be better achieved by supplementing human capabilities with computer power in order to generate these complex trajectories and to control the robot manipulator, respectively. In addition, a control strategy for robot manipulators maybe based on the coupling of the fuzzy logic control with so-called sliding mode control [2].

Robot manipulators can be classified by several criteria, for example power source, way in which the joints are actuated, geometry, kinematic structure, planned application area, method of control. Such classification is valuable fundamentally in order to determine which robot is right for a given task [3]. Kinematic analysis of the mechanical structure of a robot concerns the description of the motion with respect to a fixed reference Cartesian frame by ignoring the forces and moments that cause motion of the structure. It is meaningful to distinguish between kinematics and differential kinematics [4]. There are multi robot motion planning methods such as artificial potential field method, configuration space method, and method based on the fuzzy logic [5, 6, 7, and 8].

Zavlangas [9], applied the fuzzy method in the motion planning for a 3-DOF robot. Ranjbar et al., [10] presented an original solution and analytical comparison to path planning for manipulator arms. Corradini et al., [11] proposed control approach was based on a discrete-time sliding mode control where radial basis function neural networks were used to learn about uncertainties affecting the system. Dongbing $\mathrm{Gu}$, et al., [12] presented a new path-tracking scheme for a mobile robot based on neural Predictive control, A multi-layer back propagation neural network to model non-linear kinematics of the robot estimator in order to adapt the robot to a big operating range.

In this paper, a Joint space path planning using fuzzy logic method is presented for several links industrial robots operating in two runs using MATLAB.

\section{FUZZY LOGIC}

Fuzzy set theory, has become a popular tool for control applications in recent years. Fuzzy control has been used extensively in applications such as servomotor and process control. One of its main benefits is that it can incorporate a human being's expert knowledge about how to control a system, without that a person need to have a mathematical description of the problem. most known fuzzy models in the literature are Mamdani fuzzy model and Takagi-Sugeno-Kang (TSK) fuzzy model [13], Figure (1) shows structure of fuzzy inference system (FIS) [14].

The advantage of fuzzy logic not only fast response, low cost and good real-time ability also it is not necessary to know the exact model of the object or process to be controlled when apply the fuzzy logic control and it meet the real- time requirements for robot motion planning [15]. 


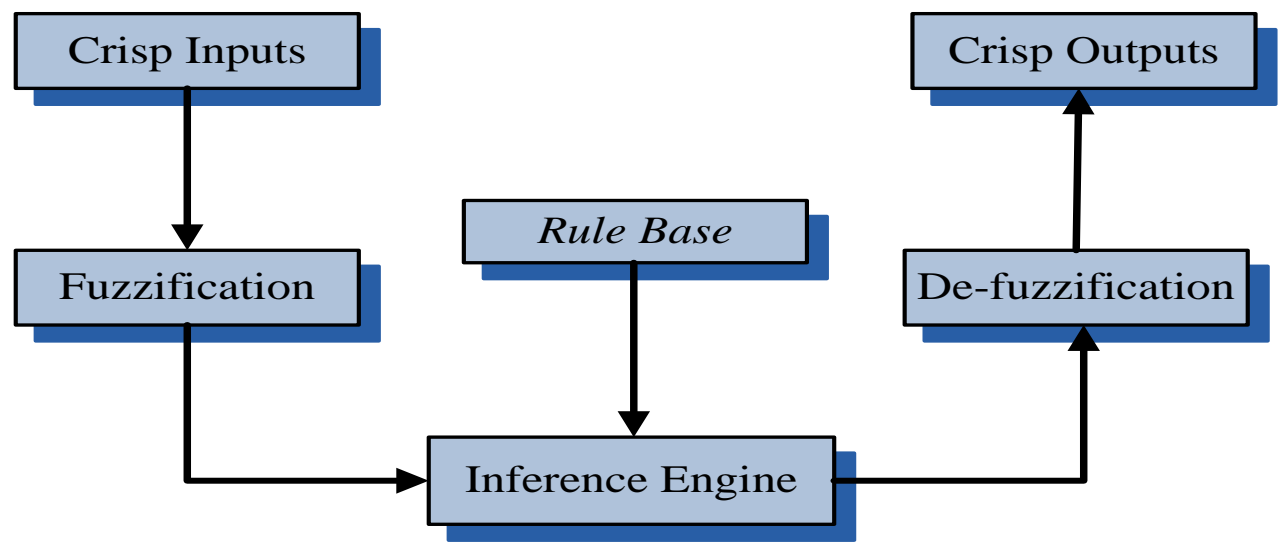

Fig 1: Structure of fuzzy inference system (FIS) [14].

\section{OVERALL STRUCTURE}

Each block produces $\Delta \theta_{n}(i+1)$ depending on the first input $\Delta \theta_{n}(i+1)$ the error between the goal value and the current value of $\left(\theta_{n}\right)$ and on the current value $\theta_{\mathrm{n}}(i)$ which represents the second input to the fuzzy block, where $n=$ $1,2, \ldots$. last link respectively. Furthermore: $\theta_{n}(i+1)=$ $\theta_{n}(i)+\Delta \theta_{n}(i+1)$ and $\theta_{g n}-\theta_{n}(i)=\Delta \theta_{g n}(i+1)$ Figure (2) shows overall scheme of our system.

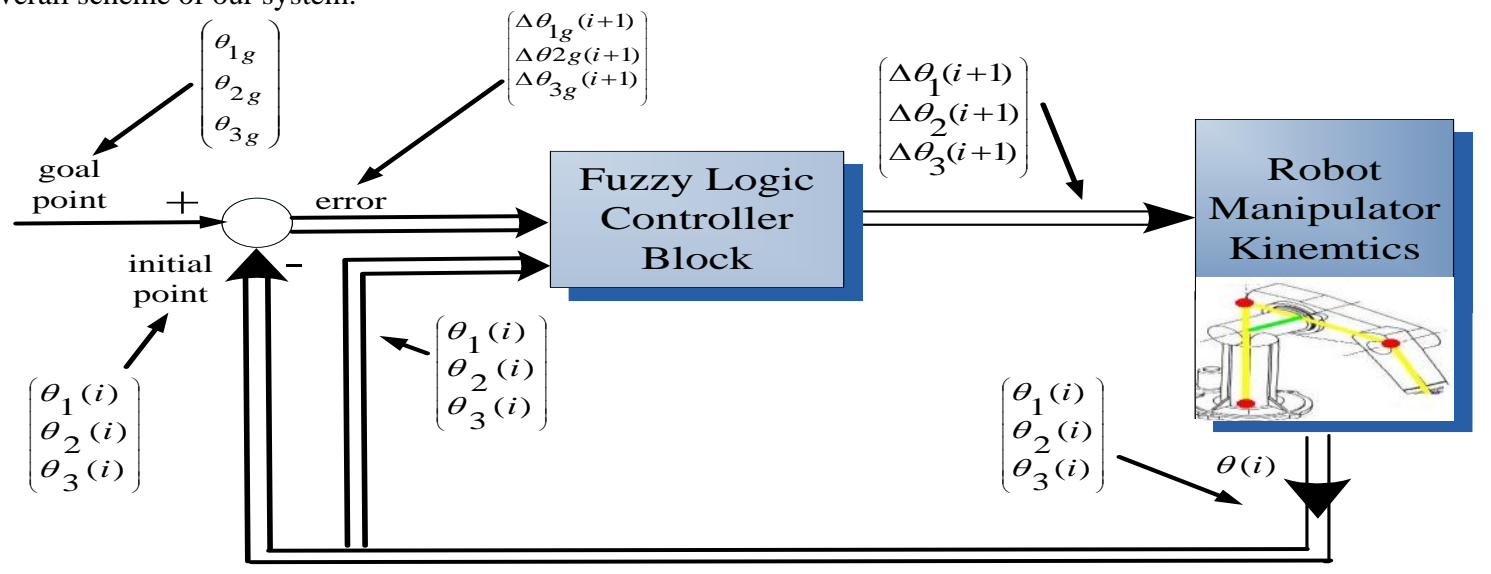

Fig 2: Fuzzy logic structure for navigation of a multi-link robot manipulator

Moreover, some of membership function after modelled this structure in MATLAB using fuzzy logic are plotted in Figure (3, 4 and 5) as shown below.

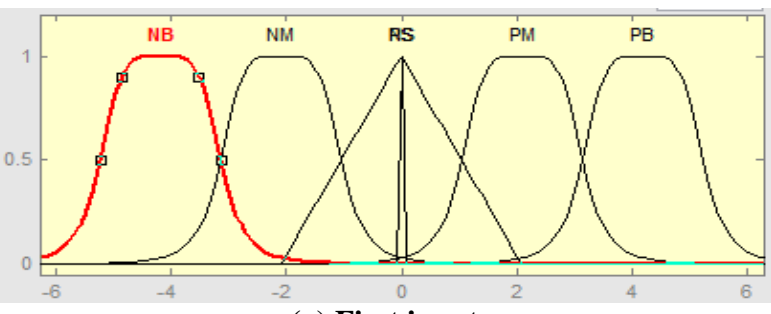

(a) First input

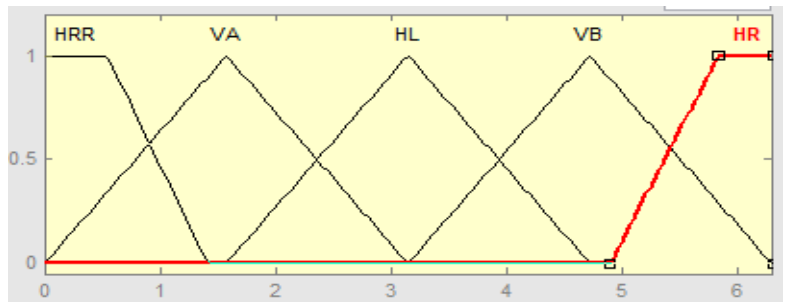

(b) Second input

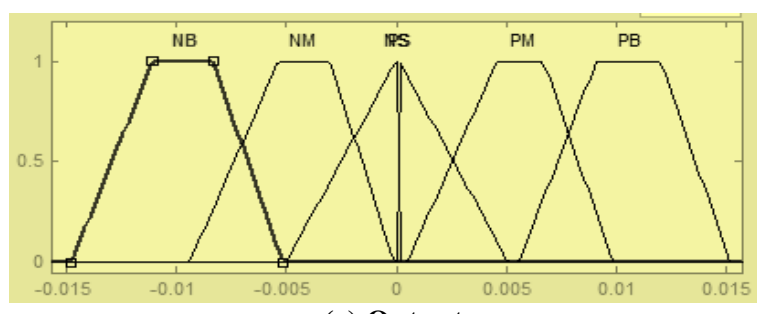

(c) Output

Fig 3: Membership function plots of first link

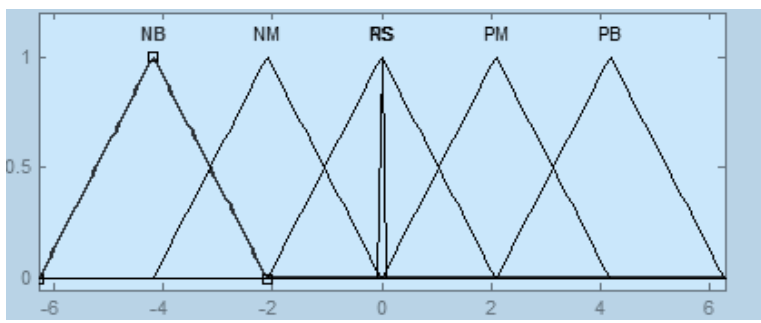

(a) First input 


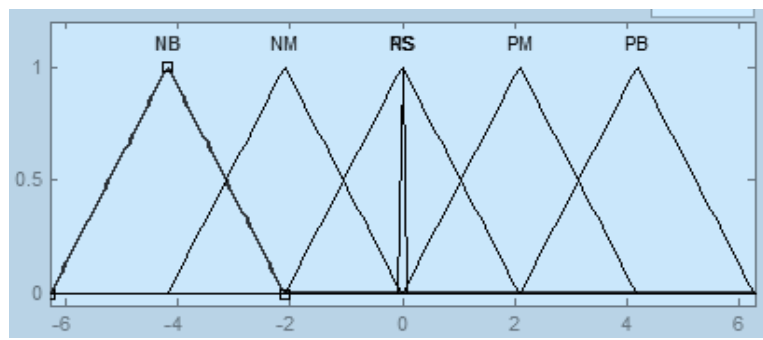

(b) Second input

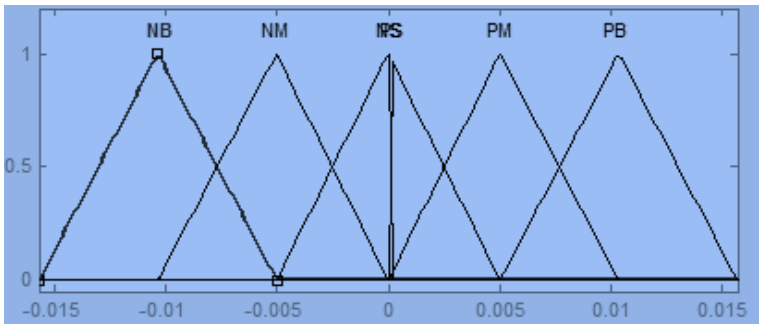

(c) Output

Fig 4: Membership function plots of the other link

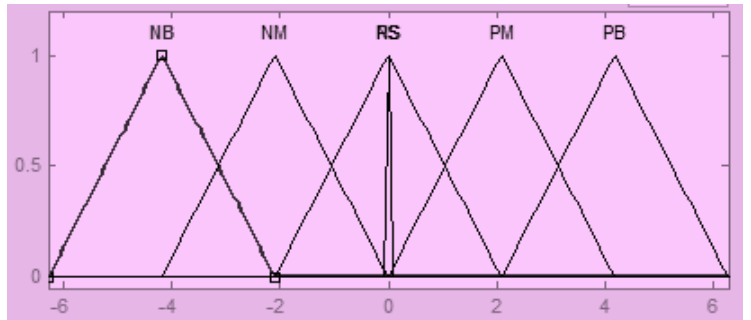

(a)First input

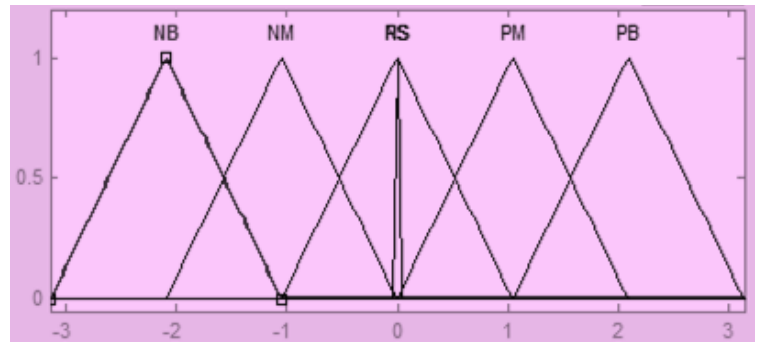

(b) Second input

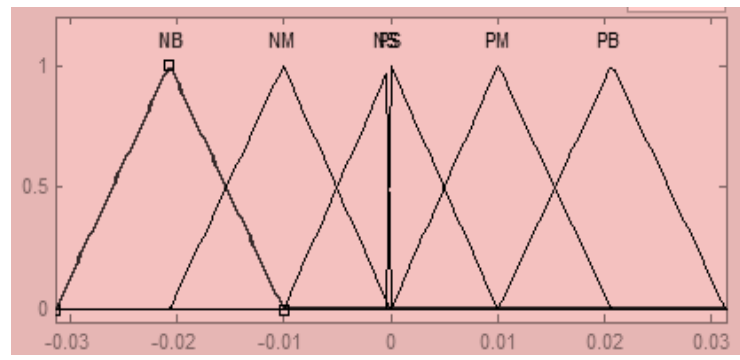

(c) Output

Fig 5: Membership function plots of the last link

In these figures the design made for the robot manipulator in the computer modeling. The rules used for fuzzy block to produce the proper output using the Mamdani method.

For example below the rules of the first link will be as:

If $\left(\Delta \theta_{1 g}(i+1)\right.$ is $\left.\mathrm{NB}\right)$ and $\left(\theta_{1}(i)\right.$ is HL) then $\left(\Delta \theta_{1}(i+1)\right.$ is $\mathrm{NB})$

If $\left(\Delta \theta_{1 g}(i+1)\right.$ is NB) and $\theta_{1}(i)$ is HRR $)$ then $\Delta \theta_{1}(i+1)$ is $\mathrm{NM})$

If $\left(\Delta \theta_{1 g}(i+1)\right.$ is $\left.\mathrm{NM}\right)$ and $\theta_{1}(i)$ is $\left.\mathrm{VB}\right)$ then $\Delta \theta_{1}(i+1)$ is $\mathrm{NS})$

If $\left(\Delta \theta_{1 g}(i+1)\right.$ is NM) and $\theta_{1}(i)$ is HR2) then $\Delta \theta_{1}(i+1)$ is $\mathrm{NB})$

If $\left(\Delta \theta_{1 g}(i+1)\right.$ is NS $)$ and $\theta_{1}(i)$ is HR2) then $\Delta \theta_{1}(i+1)$ is $\mathrm{NS})$

If $\left(\Delta \theta_{1 g}(i+1)\right.$ is $\left.\mathrm{S}\right)$ and $\theta_{1}(i)$ is $\left.\mathrm{VB}\right)$ then $\Delta \theta_{1}(i+1)$ is PS)

Also the rules of the other link will be as:

If $\left(\Delta \theta_{2 g}(i+1)\right.$ is $\left.\mathrm{NM}\right)$ and $\theta_{2}(i)$ is $\left.\mathrm{PB}\right)$ then $\Delta \theta_{2}(i+1)$ is $\mathrm{NS})$

If $\left(\Delta \theta_{2 g}(i+1)\right.$ is NS) and $\theta_{2}(i)$ is PM) then $\Delta \theta_{2}(i+1)$ is $\mathrm{NB})$

If $\left(\Delta \theta_{2 g}(i+1)\right.$ is PS) and $\theta_{2}(i)$ is $\left.\mathrm{NB}\right)$ then $\Delta \theta_{2}(i+1)$ is NS)

If $\left(\Delta \theta_{2 g}(i+1)\right.$ is PS) and $\theta_{2}(i)$ is NS) then $\Delta \theta_{2}(i+1)$ is NS)

If $\left(\Delta \theta_{2 g}(i+1)\right.$ is PS $)$ and $\theta_{2}(i)$ is PS $)$ then $\Delta \theta_{2}(i+1)$ is PS $)$ If $\left(\Delta \theta_{2 g}(i+1)\right.$ is PM) and $\theta_{2}(i)$ is NS) then $\Delta \theta_{2}(i+1)$ is PS)

Moreover the rules of the last fuzzy block for last link will be as:

If $\left(\Delta \theta_{3 g}(i+1)\right.$ is $\left.\mathrm{NB}\right)$ and $\theta_{3}(i)$ is $\left.\mathrm{PB}\right)$ then $\Delta \theta_{3}(i+1)$ is $\mathrm{NB})$

If $\left(\Delta \theta_{3 g}(i+1)\right.$ is $\left.\mathrm{NM}\right)$ and $\theta_{3}(i)$ is NS) then $\Delta \theta_{3}(i+1)$ is $\mathrm{NM})$

If $\left(\Delta \theta_{3 g}(i+1)\right.$ is $\left.\mathrm{NM}\right)$ and $\theta_{3}(i)$ is $\left.\mathrm{PB}\right)$ then $\Delta \theta_{3}(i+1)$ is NS)

If $\left(\Delta \theta_{3 g}(i+1)\right.$ is NS) and $\theta_{3}(i)$ is NM) then $\Delta \theta_{3}(i+1)$ is $\mathrm{NB})$

If $\left(\Delta \theta_{3 g}(i+1)\right.$ is PS $)$ and $\theta_{3}(i)$ is $\left.\mathrm{NB}\right)$ then $\Delta \theta_{3}(i+1)$ is NS)

If $\left(\Delta \theta_{3 g}(i+1)\right.$ is PS) and $\theta_{3}(i)$ is NS) then $\Delta \theta_{3}(i+1)$ is NS)

The most popular methods to calculate the fuzzy intersection (fuzzy-AND) operation according the fuzzy rules are the minimum and product operators. The final output of every fuzzy block can be computed using the center of gravity (COG) defuzzification method over all rules [16].

$\tau_{j}=\frac{\sum_{\tilde{r}_{j}=1}^{r_{j}} \sigma_{\tilde{r}_{j}} \cdot \tau_{\tilde{r}_{j}}}{\sum_{\tilde{r}_{j}=1}^{r_{j}} \sigma_{\tilde{r}_{j}}}$. Where: $\tilde{r}_{j}=1, \ldots, r_{j}$, below Table show list of symbols and meaning. 
Table 1. List of symbols and meaning

\begin{tabular}{|c|c|c|c|}
\hline Symbols & Meaning & Symbols & Meaning \\
\hline PB & Positive Big & NB & Negative Big \\
\hline PM & $\begin{array}{l}\text { Positive } \\
\text { Medium }\end{array}$ & NM & Negative Medium \\
\hline PS & $\begin{array}{l}\text { Positive } \\
\text { Small }\end{array}$ & NS & Negative Small \\
\hline HL & $\begin{array}{l}\text { Horizontal } \\
\text { Left }\end{array}$ & VB & Vertical Below \\
\hline HR & $\begin{array}{c}\text { Horizontal } \\
\text { Right }\end{array}$ & VA & Vertical Above \\
\hline$\Delta \theta_{1}(i+1)$ & $\begin{array}{c}\text { The required } \\
\text { change of } \\
\text { joint angle } \\
\Delta \theta_{1} .\end{array}$ & $\Delta \theta_{2}(i+1)$ & $\begin{array}{l}\text { The required } \\
\text { change of joint } \\
\text { angle } \Delta \theta_{2} .\end{array}$ \\
\hline $\begin{array}{c}\Delta \theta_{1 g}(i+1 \\
)\end{array}$ & $\begin{array}{l}\text { The error } \\
\text { between the } \\
\text { goal value } \\
\text { and the } \\
\text { current value } \\
\text { of } \theta_{l} \text {. }\end{array}$ & $\begin{array}{c}\Delta \theta_{2 g}(i+1 \\
)\end{array}$ & $\begin{array}{c}\text { The error } \\
\text { between the goal } \\
\text { value and the } \\
\text { current value of } \\
\theta_{2} \text {. }\end{array}$ \\
\hline$\Delta \theta_{3}(i+1)$ & $\begin{array}{c}\text { The required } \\
\text { change of } \\
\text { joint angle } \\
\Delta \theta_{3} .\end{array}$ & $\theta_{1}, \theta_{2}$ & Joint angles. \\
\hline $\begin{array}{c}\Delta \theta_{3 g}(i+1 \\
)\end{array}$ & $\begin{array}{l}\text { The error } \\
\text { between the } \\
\text { goal value } \\
\text { and the } \\
\text { current value } \\
\text { of } \theta_{3} \text {. }\end{array}$ & $\tau_{\tilde{\mathbf{r}}_{j}}$ & $\begin{array}{c}\text { a numerical entry } \\
\text { in the rule base } \\
\text { used in the } \\
\text { defuzzification } \\
\text { process. }\end{array}$ \\
\hline$\sigma_{\tilde{r}_{j}}$ & $\begin{array}{l}\text { The fuzzy } \\
\text { intersection }\end{array}$ & $r_{j}$ & $\begin{array}{l}\text { is the number of } \\
\text { rules for the } \\
\text { fuzzy unit of link } \\
\mathbf{L}_{\mathbf{j}}\end{array}$ \\
\hline FB & Fuzzy Block & FIS & $\begin{array}{l}\text { Fuzzy Inference } \\
\text { System }\end{array}$ \\
\hline
\end{tabular}

The results of the computer modeling are shown in Figure (7) where the robot has to move from the required configuration $\left(\theta_{1}=0^{0}, \theta_{2}=25^{0}, \theta_{3}=50^{0}\right)$ to the goal configuration $\left(\theta_{1}=90^{\circ}, \theta_{2}=130^{\circ}, \theta_{3}=45^{0}\right)$ the error in reaching the goal after (1233) program iterations was: $2.1235 \times 10^{-5} \mathrm{rad}$ for $\theta_{1},-0.0015 \mathrm{rad}$ for $\theta_{2},-0.0873 \mathrm{rad}$ for $\theta_{3}$.

Figure (8) shows the graphs of run1

\section{COMPUTER MODELING AND RESULTS}

Computer modeling and simulation has been done to test the overall system of Figure (4). A multi links robot arm each other equal $0.45 \mathrm{~m}$ used for this model. Figure (6) shows surface view of fuzzy blocks used for this model.

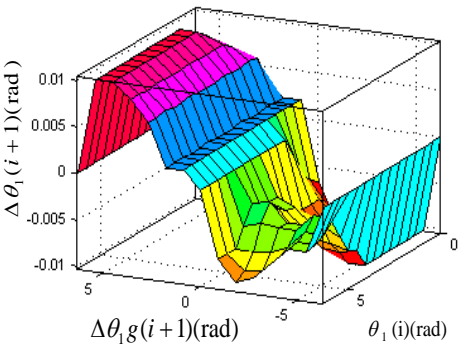

(a)

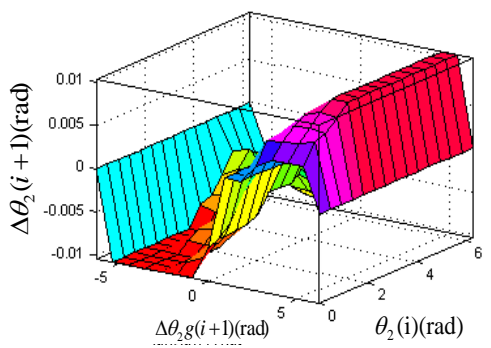

(b)

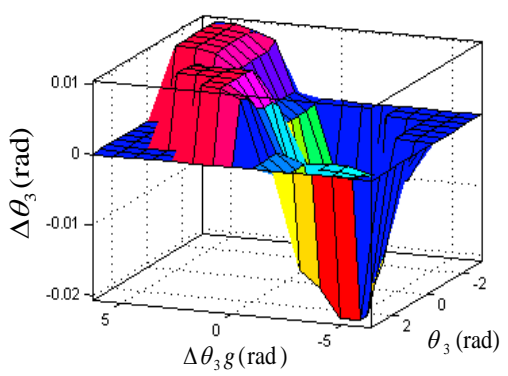

(c)

Fig 6: Surface View of: (a) FB1 $\quad$ (b) FB2 $\quad$ (c) FB3

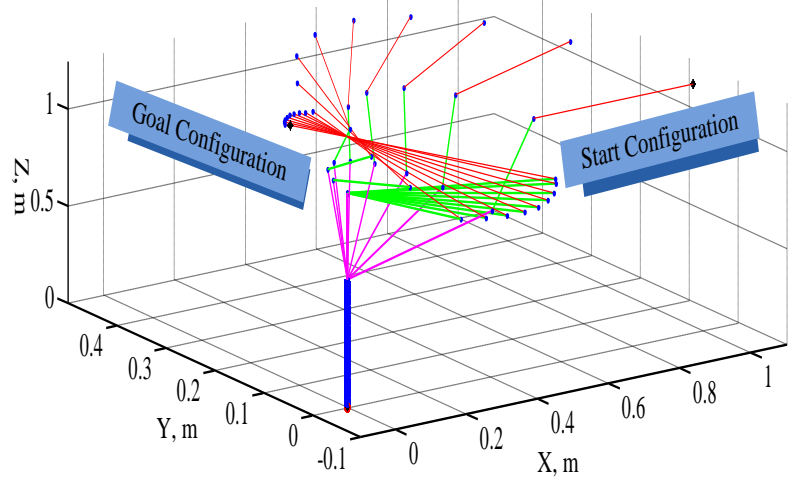

Fig 7: Multi links robot manipulator Joint space path planning using fuzzy logic of run1 

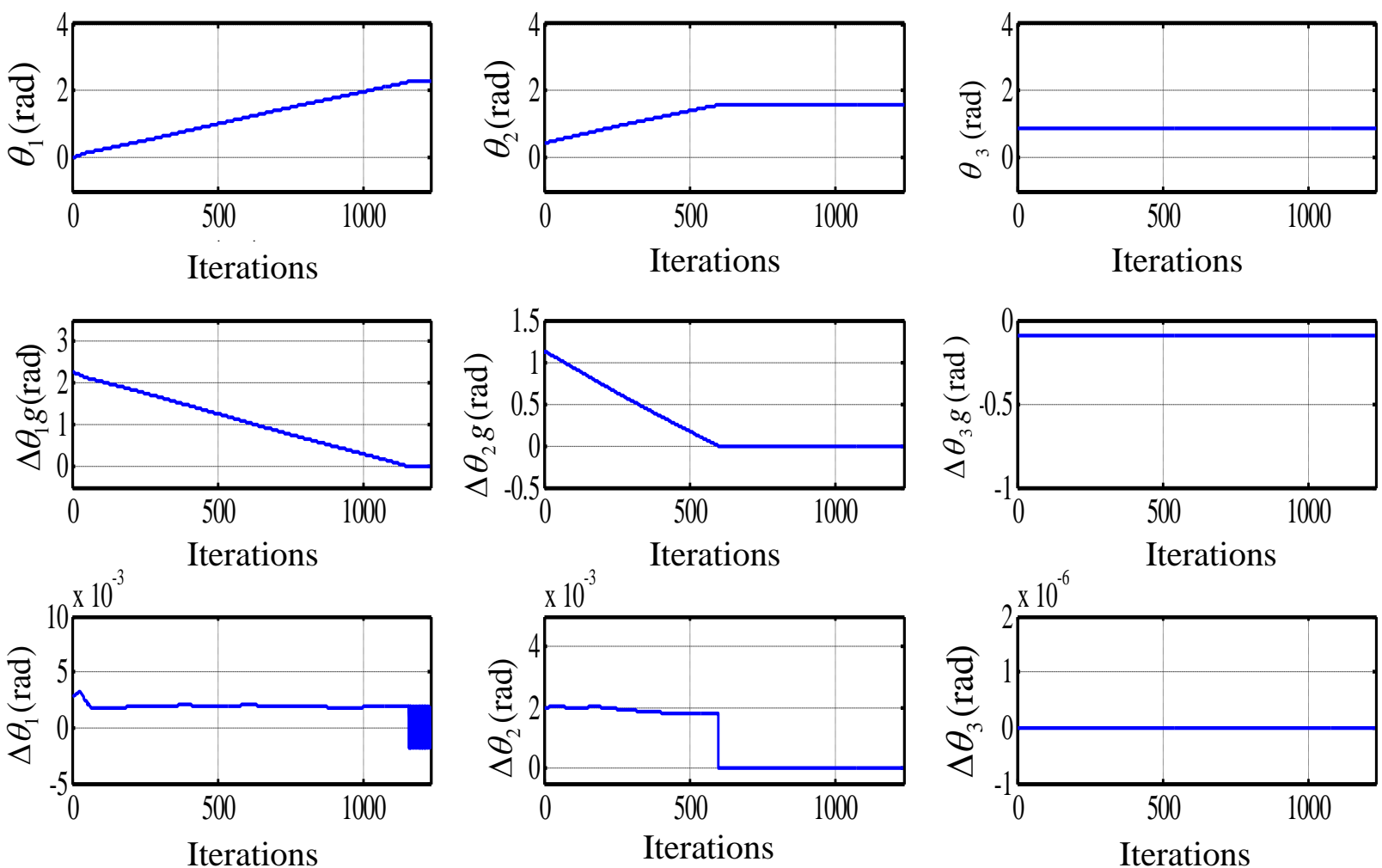

Fig 8: Change of Joint path planning parameters with program iteration index of run1

Moreover in another test, where the robot has to move from the stat to desired goal configuration the results are shown in Figure (9). The start configuration $\left(\theta_{1}=75^{0}, \theta_{2}=0^{0}, \theta_{3}=\right.$ $\left.0^{0}\right)$ to the desired goal $\left(\theta_{1}=50^{0}, \theta_{2}=90^{\circ}, \theta_{3}=160^{0}\right)$ the error in reaching the goal after (825) program iterations was8.0424 $\times 10^{-6} \mathrm{rad}$ for $\theta_{1},-2.4998 \times 10^{-4} \operatorname{rad}$ for $\theta_{2}$, $-0.0064 \mathrm{rad}$ for $\theta_{3}$.

Below Figure (10) displays this robot in the four-view window top, side, axial and 3 D)

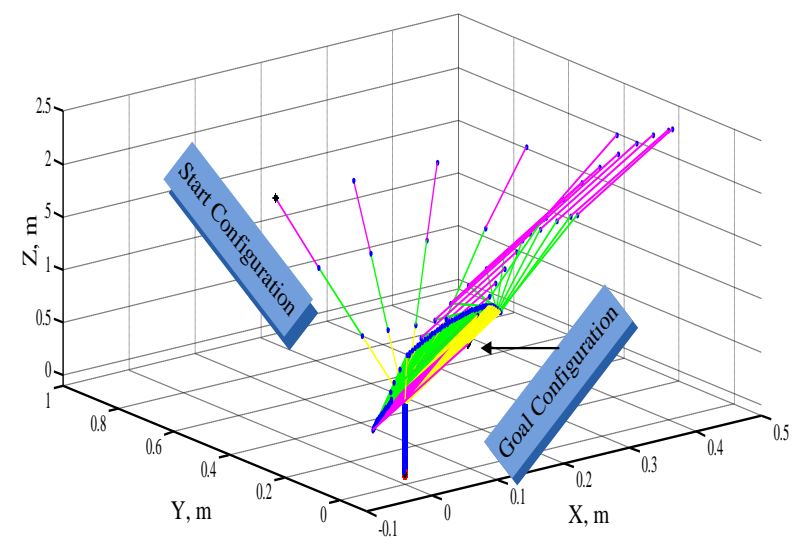

Fig 9: Multi links robot manipulator Joint space path planning using fuzzy logic of run2. 

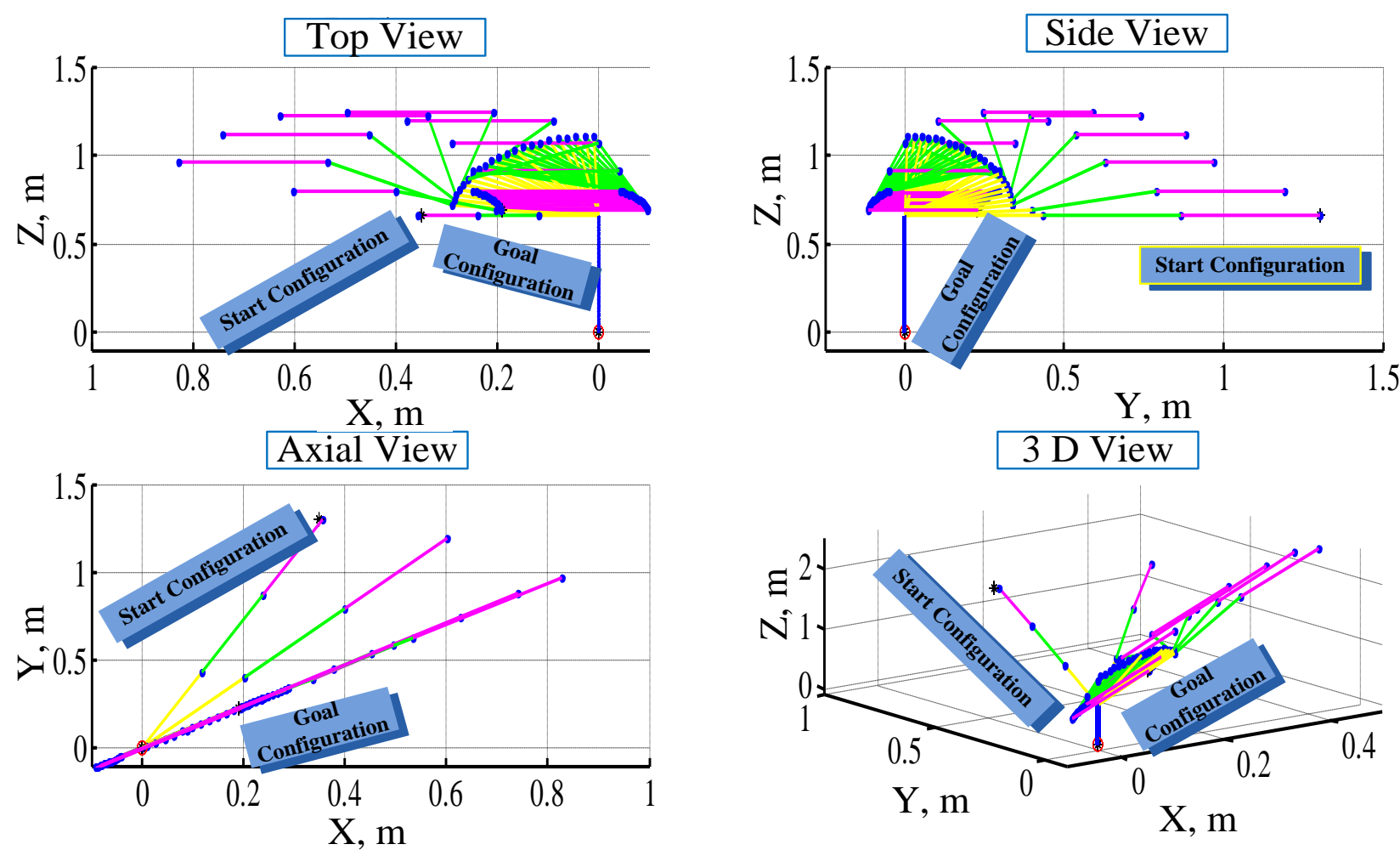

Fig 10: Four-view window (top, side, axial and $3 \mathrm{D}$ )

Figure 11 shows the graphs of $\left(x, y, z, \Delta x, \Delta y, \Delta z, e_{x}, e_{y}, e_{z}, \theta_{1}, \theta_{2}, \theta_{3}\right)$ of run2.
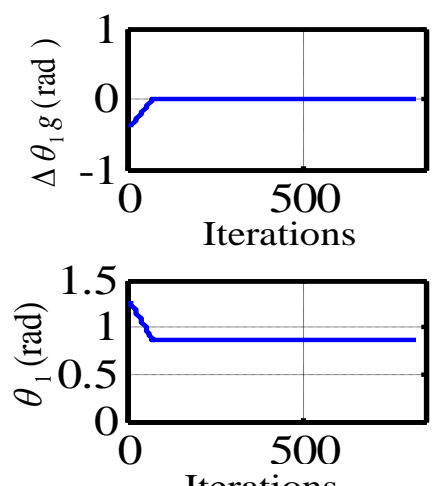

Iterations

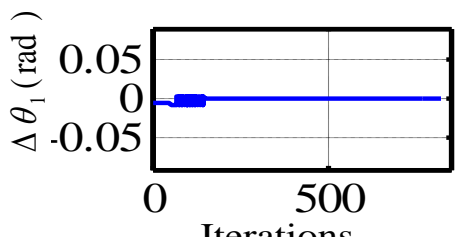

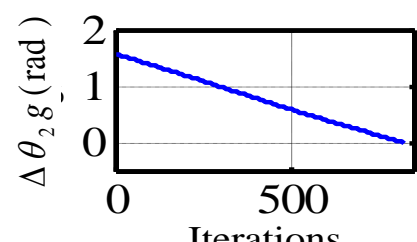

Iterations
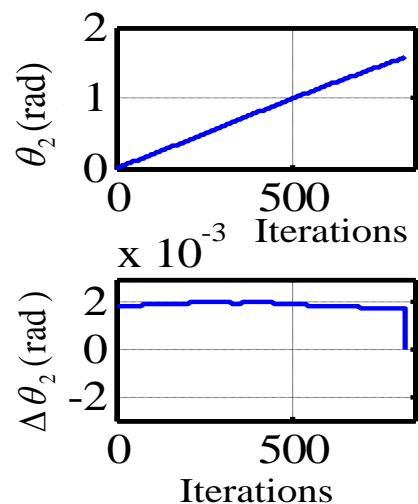

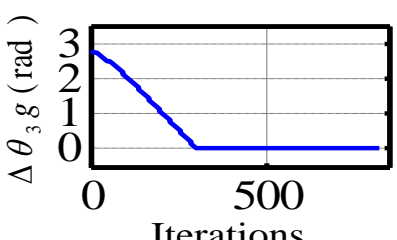

Iterations

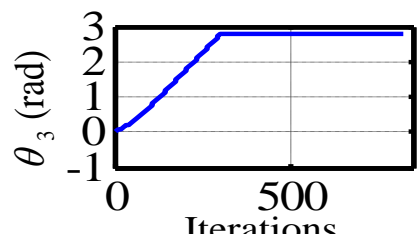

Iterations

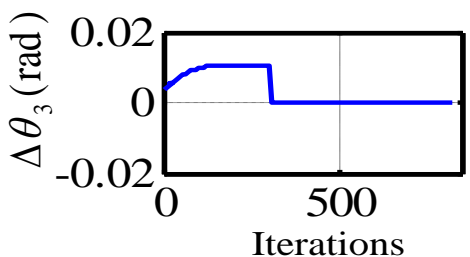

Fig 11: Change of Joint space path planning parameters with program iteration index of run2

\section{CONCLUSION}

This planning system in Joint space showed good results since the error of reaching the goal configuration after program iterations was without motion oscillation of the robot near the

goal configuration. In the first run, the robot moved from a required configuration to a desired goal configuration with minimal error with program iteration (1233).

In the second run the results showed also a minimum error with less program iterations (825) in another start and goal configuration. Future scope is genetic algorithm system for this planning in a future work study.

\section{REFERENCES}

[1] Melek W. W., 2010. "ME 547: Robot Manipulators: Kinematics, Dynamics, and Control". Waterloo, ON, University of Waterloo, pp.1-3.

[2] Amer A. F. , Sallam E. A., and Elawady W. M., 2011. "Adaptive Fuzzy Sliding Mode Control using Supervisory Fuzzy Control for 3 DOF Planar Robot 
Manipulators", Robotics and Autonomous Systems, Vol. 59, Issues 7-8, pp. 543-554, July-August.

[3] Spong M. W., Seth Hutchinson, and Vidyasagar M., 2006. "Robot Modeling and Control", $1^{\text {st }}$ Edition. John Wiley \& Sons, Inc. New York / Chichester / Weinheim / Brisbane / Singapore / Toronto. pp. 5-6, 76.

[4] Cheung E., and Lumelsky V., 1989. "Proximity Sensing in Robot Manipulator Motion Planning: System and Implementation Issues", IEEE Trans. Robotics and Automation, 5(6): 740-751. Downloaded from Iraqi Virtual science library at $8 / 2 / 2013$.

[5] Lumelsky V. J., Shur M. S., and Wagner S., 2001. "Sensitive Skin", IEEE Sensors Journal, 1(1): 41-51.

[6] Cheung E., and Lumelsky V., 1989. "Development of Sensitive Skin for A 3D Robot Arm Operating in an Uncertain Environment", IEEE International Conference on Robotics and Automation, 12: 1056-1061.

[7] Cheung E., and Lumelsky V., 1990. "Motion Planning for a Whole-Sensitive Robot Arm Manipulator", IEEE International Conference on Robotics and Automation, 1: 344-349.

[8] Wei W. and Shimin W., 2011. "3-D Path Planning using Neural Networks for a Robot Manipulator", IEEE computer society pp. 3-6. Downloaded from Iraqi Virtual science library at 3/11/2011.

[9] Zavlangas P. G. and Tzafestas S. G., 2000. "Industrial Robot Navigation and Obstacle Avoidance Employing
Fuzzy Logic", Journal of Intelligent and Robotic Systems Vol. 27: pp. 85-97.

[10] Ranjbar B., Mahmoodi J., Karbasi H., Dashti G. and Omidvar A., 2015. "Robot Manipulator Path Planning Based on Intelligent Multi-resolution Potential Field" International Journal of $\mathrm{u}$ - and e- Service, Science and Technology Vol.8, No.1, pp.11-26.

[11] Corradini L. M., Giantomassi A., Ippoliti G, Longhi S. and Orlando G., JANUARY 2013. "Robust Control of Robot Arms via Quasi Sliding Modes and Neural Networks", Advances and Applications in Sliding Mode Control systems, pp. 1-1.

[12] Dongbing Gu and Huosheng Hu., "Neural Predictive Control for a Car-like Mobile Robot" International Journal of Robotics and Autonomous Systems, Vol. 39, No. 2-3, May, 2002.

[13] Stoian V., Ivanescu M., "Robot Control by Fuzzy Logic", Frontiers in Robotics, Automation and Control, InTech, pp.111-111, 01, October, 2008.

[14] http://www.codeproject.com/KB/recipes/Fuzzinator/Fuzz ySystem.png. Downloaded at 13/5/2015.

[15] Yi-liF. , Bao J., Han L., and Shu-guo W., "A Robot Fuzzy Motion Planning Approach in Unknown Environments for Three-Degree Industrial Robots", higher education press and springer-verlag, Vol. 3, pp. 336-340, 2006

[16] Althoefer K. "Neuro-Fuzzy Motion Planning for Robotic Manipulators", Ph. D. Thesis, CH 4, pp. 120-144, 1996. 